\title{
Immunological alterations during the clinical and recovery phases of experimental swine dysentery
}

\author{
Robert Jonasson, ${ }^{1}$ Märit Andersson, ${ }^{1}$ Therese Råsbäck, ${ }^{2}$ \\ Anders Johannisson ${ }^{3}$ and Marianne Jensen-Waern ${ }^{1}$ \\ Department of Clinical Sciences ${ }^{1}$, Section for Comparative Physiology and Medicine; \\ Department of Clinical Sciences ${ }^{2}$ and Department of Anatomy and Physiology ${ }^{3}$, Swedish \\ University of Agricultural Sciences, PO Box 7018, S-750 07 Uppsala, Sweden
}

Correspondence

Robert Jonasson

Robert.Jonasson@kv.slu.se

Received 24 January 2006 Accepted 27 March 2006

\section{INTRODUCTION}

Taylor and Alexander (1971) showed that swine dysentery is caused by the Gram-negative spirochaete Brachyspira hyodysenteriae. The main clinical signs are severe mucohaemorrhagic diarrhoea and a reduced general appearance. The typical manifestations in the large intestine are excessive mucus production, haemorrhage and tissue necrosis. Due to the increased antimicrobial resistance of B. hyodysenteriae to the few antibiotic treatments available (Lobova et al., 2004), a better knowledge of the host responses during infection is essential for development of prophylactic measures. In pigs, macrophages and neutrophils are found in colonic lesions at later stages of swine dysentery, but the role of these cells is still unclear (Albassam et al., 1985). Experimental infections with B. hyodysenteriae in mice demonstrate that neutrophils are of great importance in mediating the severe oedema and structural lesions that occur in the intestine during the infection (Sacco et al., 2000), and may thus be part of the

Abbreviations: $\mathrm{PE}$, phycoerythrin; $\mathrm{SAA}$, serum amyloid $\mathrm{A}$. pathogenesis. However, the commensal intestinal flora has also been shown to be necessary for the development of the disease (Whipp et al., 1979; Neef et al., 1994). Among lymphocyte subsets, $\mathrm{CD} 8^{+}$cells appear to be of particular importance in the genesis of swine dysentery (Waters et al., 1999a, b; Jonasson et al., 2004), with low levels of circulating $\mathrm{CD} 8 \alpha^{+}$cells and high levels of circulating $\gamma \delta \mathrm{T}$ cells before experimental inoculation shown to increase susceptibility to swine dysentery (Jonasson et al., 2004). The mechanism of action of $\mathrm{CD}^{+}$cells against $B$. hyodysenteriae is largely unknown, but immune-mediated mucosal damage in mice has been shown to be prevented by $\mathrm{CD} 8^{+} \mathrm{T}$ cells (Jones et al., 2002). $\mathrm{CD}^{+}$cells are important producers of IFN- $\gamma$ (Steele et al., 2002), which activates macrophages (Murray, 1990) and may also enhance their response against $B$. hyodysenteriae. In a study by Hontecillas et al. (2002), swine-dysenteryaffected pigs had upregulated expression of IFN $-\gamma$ in colonic lymph nodes.

The duration and characteristics of the immune response in the recovery period after the acute phase of dysentery have 
not been studied thoroughly. It has been shown that pigs that have recovered from swine dysentery are immune to reinfection (Joens et al., 1979, 1983). This immunity appears to be antibody mediated, since colonic loops are protected against infection after passive transfer of convalescent serum antibodies (Joens et al., 1979; Harris \& Glock, 1981). While $B$. hyodysenteriae-specific antibodies have been detected during and after swine dysentery (Joens et al., 1984, 1985; Rees et al., 1989; Wright et al., 1989), they have not been related to recovery from disease but instead regarded as an indication of prolonged or recent exposure to B. hyodysenteriae (Rees et al., 1989). To date, the protection induced by vaccines has only been associated with reduced severity of lesions without decreasing bacterial shedding (Waters et al., 1999a, b; Hontecillas et al., 2002) or induction of B. hyodysenteriae-specific IgA secretion (La et al., 2004). Thus, the relative importance of cell-mediated and antibodymediated immunity for the recovery from infection with $B$. hyodysenteriae is not known.

The present study was therefore designed to allow examination of the proportional changes in some selected subpopulations of porcine blood lymphocytes and the development of specific antibodies during incubation, the acute phase and the recovery period of experimentally induced swine dysentery.

\section{METHODS}

Animals and housing. The Ethical Committee for Animal Experiments, Uppsala, Sweden, approved the experimental design.

Ten clinically healthy crossbred pigs (Yorkshire $\times$ Swedish Landrace) of mixed sexes were obtained at the age of 8-10 weeks from a conventional piglet-producing herd known to be free from swine dysentery. This herd is regularly health-monitored by swine specialists from the university. Following arrival at the experimental facilities at the Department of Clinical Sciences, the animals were acclimatized for at least 1 week. The pigs were housed individually, were fed twice daily with a commercial finisher diet without growth promoters (Singelveg SPK, Lantmännen) and had free access to water. The pens had concrete floors with straw as bedding material during acclimatization and synthetic fur blankets during the experimental period in order to minimize fibre ingestion. Faecal samples taken from all pigs at arrival were analysed by routine methods and found negative to parasite eggs, Brachyspira spp., Salmonella spp. and Yersinia spp. The pigs, which had a mean weight of $23 \mathrm{~kg}$ (range $20-29 \mathrm{~kg}$ ) before inoculation, were weighed once a week for calculation of daily weight gain (DWG). The DWG was divided by the animals' live weight in order to avoid the effect of different growth rates during the fattening period.

Experimental design. The infection model included a provocative feeding regime that has previously been shown to facilitate infection with B. hyodysenteriae (Jacobson et al., 2004). Briefly, 4 days prior to inoculation with $B$. hyodysenteriae, all pigs were fed a diet in which the commercial diet was substituted with pure soybean meal on every second feeding occasion for 7 consecutive days. During the last 3 days of this feeding regime, the pigs were inoculated orally once daily with $30 \mathrm{ml}$ brain heart infusion (BHI) broth containing approximately $10^{7}-10^{9}$ bacteria $\mathrm{ml}^{-1}$ of $B$. hyodysenteriae strain $\mathrm{B} 204^{\mathrm{T}}$ (ATCC 31212). The bacteria were propagated according to Fellström \& Gunnarsson (1995), and bacterial growth, purity and motility were evaluated with phase-contrast microscopy.
Thorough clinical health examinations, including measurement of rectal temperature and evaluation of faeces with respect to consistency, and the presence of blood and mucus, were performed daily. The initial onset of signs of diarrhoea was defined as day 1 of the swine dysentery period. The time-point when the faecal consistency changed from diarrhoea to slightly loose or normal was defined as day 1 of the recovery period. The pigs that developed swine dysentery were euthanized approximately 20 days after recovery, and the pigs that remained clinically healthy throughout the study were euthanized 35 days after inoculation. After induction of anaesthesia with a mixture of $0.05 \mathrm{mg} \mathrm{kg}^{-1}$ medetomidine (Domitor vet) and $5 \mathrm{mg} \mathrm{kg}^{-1}$ Zoletil (tiletamine + zolazepam), euthanasia was performed with an overdose of pentobarbital sodium. A complete necropsy was performed on all animals.

Sampling of faeces and blood. Rectal swabs for culturing and detection of Brachyspira spp. were collected once a week until clinical signs of swine dysentery occurred, daily during the clinical signs of dysentery, and then once a week during the recovery period. Samples were cultured and evaluated according to Fellström \& Gunnarsson (1995). Jugular venous blood was obtained in vacuum tubes from all pigs before the soybean diet and inoculum was given, and then 4 and 14 days after the last day of inoculation. During the acute phase with clinical signs of disease, blood was also sampled for 4 consecutive days, and then at days 1, 3, 7, 11 and 15 of the recovery period. Pigs that did not develop any clinical signs of disease were sampled once a week until the euthanasia that was performed after all of the dysenteric animals had recovered.

Analysis of peripheral blood leukocytes. Total and differential white blood cell counts were analysed with an electronic cell counter (Cell-Dyn 3500, Abbott). EDTA blood samples were rotated at room temperature until immunostaining, which was performed within $12 \mathrm{~h}$, as previously described (Jonasson et al., 2004). Briefly, erythrocytes were lysed, followed by centrifugation. The resulting leukocyte pellet was then washed twice and resuspended in PBS with fetal calf serum (FCS). Cells $\left(0.5 \times 10^{6} \mathrm{ml}^{-1}\right)$ were double-stained using monoclonal antibodies (VMRD) or isotype controls (DakoCytomation) as primary antibodies, as in Table 1. After washing, the cells were incubated with phycoerythrin (PE)- and FITC-conjugated secondary antibodies (CALTAG). The cells were washed, resuspended and finally fixed in PBS with paraformaldehyde until flow cytometric analyses were performed.

\section{Flow cytometric analyses}

A total of 30000 cells per sample were analysed by forward light scatter and orthogonal light scatter in a BD LSR flow cytometer (BDBiosciences). Lymphocytes were gated using the light-scatter parameters and further evaluated for FITC and/or PE fluorescence. The results were evaluated by region analysis, except for the CD4/CD8 $\alpha$ double staining (no. 3 in Table 1), for which quadrant analysis was used. Evaluation was performed with the Cellquest software (BDBiosciences). The proportion of stained cells was multiplied by the number of lymphocytes determined in the total and differential counts in order to calculate the absolute number of lymphocytes in the various subpopulations.

Analysis of serum amyloid A (SAA). Blood samples without additives were centrifuged at $1500 \mathrm{~g}$ and serum was collected and stored at $-80{ }^{\circ} \mathrm{C}$ until analysed. The analysis of SAA was performed on serum samples diluted $1: 500$, using a commercially available ELISA (Tridelta Phase range SAA kit, Tridelta Development).

\section{Analysis of serum antibodies}

Sera from the following six sampling occasions were used: before the soybean diet and inoculum was given, at day 2 of clinical signs of 
Table 1. Monoclonal primary antibodies used during the double-staining procedure

\begin{tabular}{|c|c|c|c|c|}
\hline \multirow{2}{*}{$\begin{array}{l}\text { Double- } \\
\text { staining no. }\end{array}$} & \multicolumn{2}{|c|}{ Anti-IgG1 FITC conjugate } & \multicolumn{2}{|c|}{ Anti-IgG2a PE conjugate } \\
\hline & IgG1 isotype & Clone no. & IgG2a isotype & Clone no. \\
\hline $1^{*}$ & - & - & - & - \\
\hline 2 & Isotype control & X0931 & Isotype control & X0943 \\
\hline 3 & $\mathrm{CD} 8 \alpha$ & РT36B & $\mathrm{CD} 4$ & PT90A \\
\hline 4 & $\mathrm{CD} 8 \alpha$ & РТ36B & $\mathrm{CD} 8 \beta$ & PG164A \\
\hline 5 & $\gamma \delta(\mathrm{Po}-\mathrm{TcR} 1-\mathrm{N} 4)$ & PGBL22A & CD45 RA & PGB78A \\
\hline 6 & $\mathrm{CD} 21$ & BB6-11C9 & CD45 RA & PGB78A \\
\hline
\end{tabular}

${ }^{\star}$ Auto-fluorescence control (no antibodies added).

dysentery and at days 1, 7, 11 and 15 of the recovery period. For the healthy pigs, the following three sampling times were used: before the soybean diet and inoculum was given, and 14 and 28 days after challenge. Sera from each pig at these separate sampling occasions were pooled, resulting in six pooled samples for the dysenteric pigs and three for the healthy pigs. In addition, sera from each of the swine-dysenteryaffected pigs at recovery days 7, 11 and 15 were analysed separately for serum antibodies.

Analyses were performed with both unabsorbed and absorbed sera. The absorbed sera were absorbed with the type strains Brachyspira intermedia PWS $/ \mathrm{A}^{\mathrm{T}}$ (ATCC 51140), Brachyspira innocens $\mathrm{B} 256^{\mathrm{T}}$ (ATCC 29796), Brachyspira murdochii 56-150 (ATCC 51284), Brachyspira pilosicoli P43/6/78 ${ }^{\mathrm{T}}$ (ATCC 51139) and Brachyspira aalborgi $513 \mathrm{~A}^{\mathrm{T}}$ (ATCC 43994). This procedure was performed in order to remove general antibodies to Brachyspira spp., thus leaving only those with specificity for B. hyodysenteriae strain B204 ${ }^{\mathrm{T}}$ (ATCC 31212). In brief, $100 \mu \mathrm{l}$ each of bacterial pellets of $B$. innocens and B. pilosicoli, and $10 \mu \mathrm{l}$ each of B. intermedia, B. murdochii and B. aalborgi were diluted in $1 \mathrm{ml}$ resuspension buffer $(50 \mathrm{mM}$ Tris/ $\mathrm{HCl}$, $10 \mathrm{mM}$ EDTA, $\mathrm{pH} 8 \cdot 0$ ) and sonicated on ice for $10 \mathrm{~s} 10$ times with $20 \mathrm{~s}$ intervals. Five hundred microlitres of this mixture was added to every millilitre of $1: 10$-diluted sera and incubated for $90 \mathrm{~min}$ at $37^{\circ} \mathrm{C}$ before use.

Western blot of unabsorbed or absorbed sera. Whole-cell proteins from the type strain of $B$. hyodysenteriae $\left(B 78^{\mathrm{T}}\right)$ were separated by standard SDS-PAGE, according to Laemmli (1970). Bacterial samples corresponding to $2 \mu \mathrm{g}$ protein were mixed with sample buffer containing DTT before heat treatment for $5 \mathrm{~min}$. The sample was applied to an SDS-polyacrylamide gel (12\%) with a stacking gel on top and subjected to electrophoresis in a Mini-Protean II gel system (Bio-Rad). A pre-stained, broad-range protein marker from New England Biolabs was used as size ladder. The proteins were transferred onto a PVDF membrane (Towbin et al., 1979) with a Mini Trans-Blot cell (Bio-Rad). The membrane was blocked in Trisbuffered saline (TBS) with dried non-fat milk powder (MP) and then incubated with sera (diluted $1: 100$ ) by using a multiscreen apparatus (Bio-Rad). Peroxidase-conjugated rabbit anti-swine IgG (DakoCytomation) was used as a secondary antibody. After a $30 \mathrm{~min}$ conjugate incubation on a shaker, the membranes were quickly rinsed and then washed. Bound antibodies were visualized with a chemiluminescent substrate using the ECL system and Hyperfilm ECL according to the manufacturer's instructions (Amersham Biosciences).

Statistical analyses. Data are presented as mean \pm SEM. Data were calculated from eight animals with clinical signs and two healthy animals during pre-inoculation and 4 days post-inoculation. At 14 days post-inoculation, two animals in the group with clinical signs had already developed dysentery $(n=6)$. After these sampling points, one animal had to be euthanized and data are presented from seven dysenteric animals, with the exception of days 7, 11 and 15 of the recovery period, which are the means of six animals due to missing samples from different pigs on those days. The statistical calculations were performed with SigmaStat software (SPSS Science). Analysis of variance (ANOVA, Holm-Sidak method) for repeated measures was performed to compare differences in specific cell populations and SAA between measurements. Correlation analysis was performed with the Pearson product moment correlation. The data were regarded as significantly different at $P<0 \cdot 05$.

\section{RESULTS AND DISCUSSION}

\section{Clinical signs and SAA}

The experimental protocol resulted in clinical signs of swine dysentery in eight out of 10 pigs. They developed swine dysentery with muco-haemorrhagic diarrhoea and shedding of $B$. hyodysenteriae after a mean incubation period of 17 days (range 7-31 days). Seven of the eight affected pigs recovered spontaneously without any need for treatment, but due to animal welfare considerations, one dysenteric animal had to be euthanized before termination of the experiment. Blood was collected both early and late during the incubation, the dysentery and the recovery period. Clinical signs of dysentery were evident for a mean of 7 days (range 3-17 days) before signs of recovery were observed. Five of the dysenteric pigs stopped shedding B. hyodysenteriae after a mean of 8 days of recovery, while two were still shedding at euthanasia. The two animals that remained clinically healthy did not shed B. hyodysenteriae on any occasion throughout the study. The mean daily weight gain per kilogram live weight for the swine-dysentery-affected pigs was $24 \pm 1 \mathrm{~g} \mathrm{~kg}^{-1}$ prior to disease, $0 \pm 2 \mathrm{~g} \mathrm{~kg}^{-1}$ during the disease, and $20 \pm 0 \mathrm{~g} \mathrm{~kg}^{-1}$ during the recovery period. The two animals that remained healthy had a mean daily weight gain of $25 \pm 2 \mathrm{~g} \mathrm{~kg}^{-1}$. Three of the swine-dysenteryaffected pigs showed decreased appetite during the haemorrhagic phase of the diarrhoea, but none of the animals had fever. No clinical signs of illness other than those associated with swine dysentery were observed throughout the study. SAA is considered to be a clinically relevant acute-phase protein in pigs (Heegaard et al., 1998). In the present study, 
an SAA response was observed during the first 3 days of clinical signs, which is in agreement with Jacobson et al. (2004). The SAA levels were $21 \pm 13 \mathrm{mg} \mathrm{l}^{-1}$ before inoculation and $231 \pm 187,154 \pm 90,137 \pm 82$ and $25 \pm 10 \mathrm{mg}$ $1^{-1}$, respectively, during the first 4 days of swine dysentery. At day 1 of the recovery period, the SAA level was $15 \pm 7 \mathrm{mg} \mathrm{l}^{-1}$, and at day 7 of the recovery period, it was $4 \pm 3 \mathrm{mg} \mathrm{l}^{-1}$. Even though there were large inter-individual differences in the SAA response, the majority of the animals had a 30- to 60-fold increase. However, no relationship between SAA levels and severity of clinical signs was observed. The production of SAA is induced by the presence of LPS and the pro-inflammatory cytokines IL- 1 and TNF- $\alpha$ (van Snick, 1990; for review see Jensen \& Whitehead, 1998). $B$. hyodysenteriae has been shown to possess biologically active LPS (Nuessen et al., 1982) that stimulates production of the pro-inflammatory cytokines IL-1 and TNF (Greer \& Wannemuehler, 1989) and the neutrophil chemokine IL-8 (Sacco et al., 1996). The production of SAA and its induction of tissue infiltration of monocytes and polymorphonuclear cells (Badolato et al., 1994; Xu et al., 1995; Hershkoviz et al., 1997) likely influence the cellular response of the animals affected by swine dysentery.

\section{Neutrophils, monocytes and lymphocyte subpopulations}

In accordance with a previous study (Jonasson et al., 2004), elevated levels of circulating monocytes, neutrophils and $\mathrm{CD} 8 \alpha^{+}$cells were seen during clinical signs of swine dysentery. The increase of monocytes/macrophages and neutrophils has also been shown in other studies (Wilcock \& Olander, 1979; Albassam et al., 1985). There was a two- to threefold increase of neutrophils during dysentery with a peak at the fourth day of clinical signs and at the beginning of the recovery period (Fig. 1). The migration of these neutrophils to tissues and their release of active inflammatory mediators, such as prostaglandins, NO, reactive oxygen species and hydrolytic enzymes, could be important contributors to the oedema and lesions associated with swine dysentery. This is supported by a study in which the severity of intestinal macro- and microscopic lesions, oedema, and epithelial erosions in B. hyodysenteriae-induced colitis in mice were found to be moderated when the levels of intestinal neutrophils were reduced or were zero (Sacco et al., 2000).

A twofold increase in the number of monocytes was observed during clinical signs of dysentery (Fig. 1). B. hyodysenteriae-derived LPS has been reported to induce IL-1 secretion by murine macrophages (Greer \& Wannemuehler, 1989), and increased serum concentrations of TNF- $\alpha$ have been shown following onset of swine dysentery (Nibbelink et al., 1997). Macrophages are the major producers of TNF- $\alpha$, which can facilitate lesion development, since the gastrointestinal tract is known to be sensitive to TNF- $\alpha$ (Beutler et al., 1985). Potentially, local IL-1 and TNF- $\alpha$ production by intestinal $B$. hyodysenteriae-stimulated macrophages can contribute to the pathology of swine dysentery. However, there was a positive correlation between the length of the incubation period and the preinoculation levels of peripheral monocytes (correlation coefficient $0 \cdot 76 ; P=0 \cdot 03 ; n=8$ ). This relationship was also seen in pigs in a previous study (Jonasson et al., 2004) in which the pigs with the highest levels of monocytes before inoculation had the longest incubation period (correlation coefficient $0 \cdot 73 ; P=0 \cdot 003 ; n=14$ ). In the present study, two pigs had longer incubation periods than the other animals (29 and 31 days versus the mean of $15 \pm 3$ days for the other animals), and these two also had markedly higher levels of monocytes pre-inoculation $\left(4 \cdot 0\right.$ and $3 \cdot 3 \times 10^{9} 1^{-1}$ versus the mean of $1 \cdot 7 \pm 0 \cdot 3 \times 10^{9} 1^{-1}$ for the other animals). The higher numbers of monocytes do not appear to influence the clinical development of dysentery, since in the previous study there was no difference in the monocyte levels before inoculation between animals that developed swine dysentery and those that remained healthy after inoculation (Jonasson et al., 2004). Even though only two animals remained healthy after inoculation in the present study, they did not differ notably in monocyte levels before inoculation from those that developed dysentery.

Overall, the total numbers of lymphocytes increased 4 days after inoculation and at day 1 with clinical signs of dysentery. However, large inter-individual variations in the total numbers of lymphocytes were observed during the dysentery period and the beginning of the recovery period. Therefore, it is important to examine the alterations in the different lymphocyte subpopulations. While the results of lymphocyte subpopulations in this study are presented in absolute numbers, the relative numbers, expressed as a percentage, show similar results. The $\mathrm{CD} 8 \alpha^{+}$lymphocyte subpopulations increased after inoculation. Irrespective of the presence or absence of clinical signs of dysentery, all animals, including the pigs that remained healthy (Figs 2 and 3 ), showed a similar increase in circulating $\mathrm{CD} 8 \alpha^{+}$cells, $\mathrm{CD} 8 \alpha^{+} \mathrm{CD} 4^{-}$cells and $\gamma \delta \mathrm{T}$ cells on days 4 and 14 postinoculation (Figs 2 and 3). A similar rise was seen in CD8 $\alpha^{+}$ $\mathrm{CD} 8 \beta^{+}$cells 14 days post-inoculation (Fig. 2). These increases may be a response to the introduction of novel antigens, since vaccination studies with $B$. hyodysenteriae antigens have shown increased peripheral levels of CD8 $\alpha \alpha^{+}$ $\gamma \delta$ T cells and CD8 $\alpha \alpha^{+}$natural killer cells (Bassaganya-Riera et al., 2001; Waters et al., 1999a). The response could also be directed against antigens present in the soybean meal included in the provocative diet, but since these alterations were still observed 14 days after the last soybean meal, this is less likely. Soybean is a rich source of linolenic acid, which can be converted to conjugated linolenic acid (CLA) by intestinal micro-organisms in cows (Dhiman et al., 2000). We do not know whether this conversion also occurs in pigs. However, Bassaganya-Riera et al. (2001) have shown that dietary CLA increases circulating levels of CD $8 \alpha \alpha^{+} \gamma \delta$ T cells, cytotoxic T cells and CD8 $\alpha \alpha^{+}$natural killer cells in pigs. On the other hand, these changes were observed after several weeks on a CLA-rich diet, and are thus probably not applicable to the present study. 


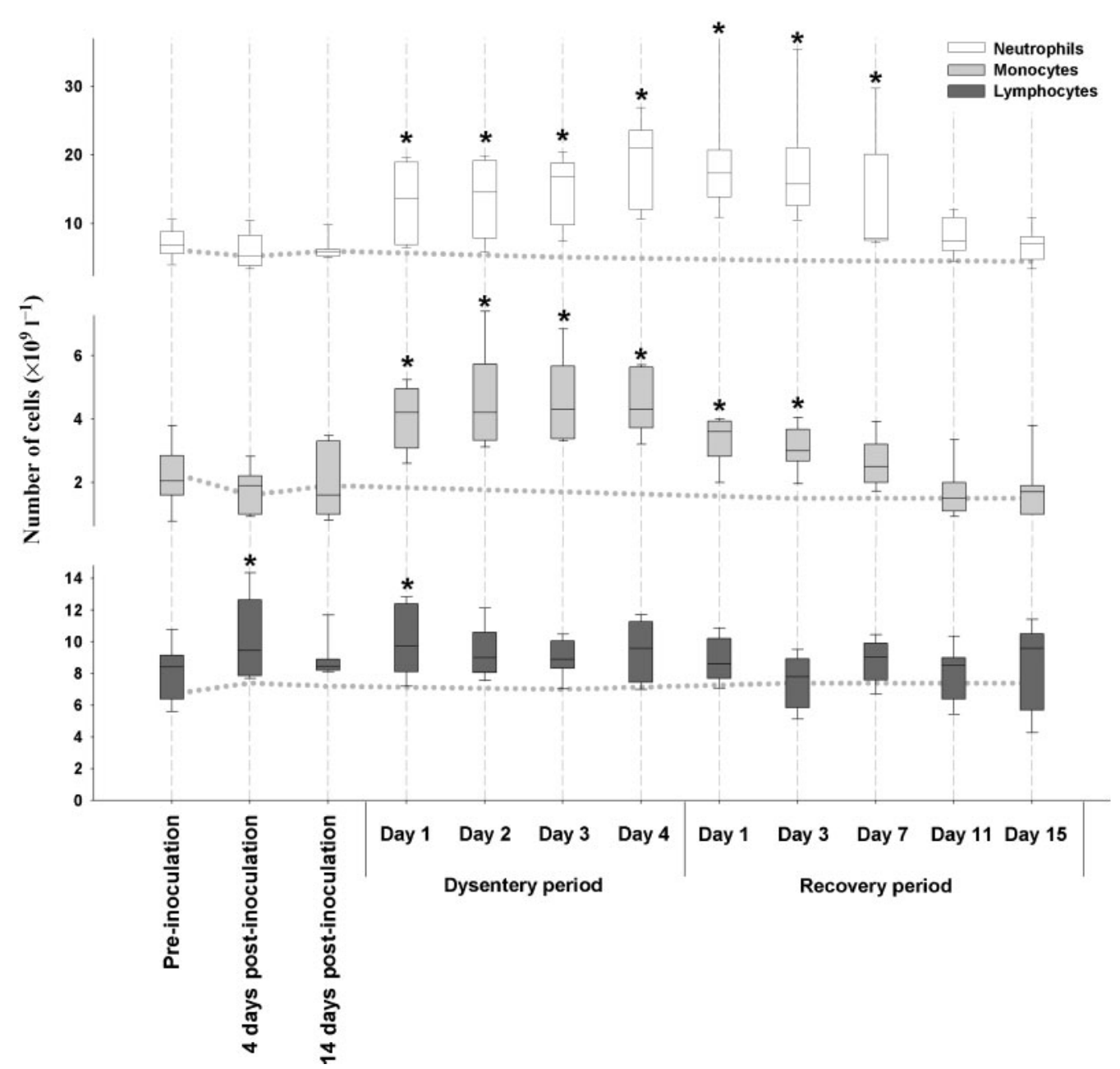

Fig. 1. Blood leukocyte populations of the dysentery-affected pigs: before inoculation, 4 and 14 days after inoculation, and during the swine dysentery and recovery periods. The mean incubation period was 17 days and the mean disease period was 7 days. The boundary of the box indicates the 25th percentile, the median and the 75th percentile. Whiskers indicate the 95th and 5th percentiles. The dotted lines behind each box plot show the average for the two animals that remained healthy. Pre-, 4 days post- and 14 days post-inoculation were the same in all animals, but the remaining sampling points for the healthy animals were from 21,28 and 35 days post-inoculation. *Significant change from pre-inoculation.

The pigs that subsequently developed dysentery showed an increase in $\mathrm{CD} 4{ }^{+} \mathrm{CD} 8 \alpha^{+}$cells at 4 days post-inoculation. Even though the numbers of animals are small, this change was not observed in the two healthy animals. High levels of extrathymic $\mathrm{CD} 4^{+} \mathrm{CD} 8^{+} \mathrm{T}$ cells are typical for pigs, and they are considered to be mature antigen-experienced memory/effector cells (Pescovitz et al., 1994; Zuckermann \& Husmann, 1996). In a previous study, it was observed that the numbers of these double-positive cells increased in the blood during clinical signs of dysentery (Jonasson et al., 2004). However, this was not observed in the present study, and their role remains unclear.

There was an increase in total $\mathrm{CD} 8 \alpha^{+}$cells during the dysentery period. The majority of these $\mathrm{CD} 8 \alpha^{+}$cells were $\mathrm{CD} 4^{-}$and also, when comparing the curve characteristics of total $\mathrm{CD} 8 \alpha^{+}$cells with those of $\mathrm{CD} 8 \alpha^{+} \mathrm{CD} 8 \beta^{+} \mathrm{T}$ cells, they appeared to be $\mathrm{CD} 8 \beta^{-}$. The increase of $\mathrm{CD} 8 \alpha^{+}$cell populations during the clinical signs of disease appears to be of importance in swine dysentery, and the involvement of these populations is in accordance with findings by Waters et al. (2000) and Jonasson et al. (2004). In the present study, the proliferation of $\mathrm{CD} 8 \alpha^{+}$cells appears to consist of CD $8 \alpha^{+}$ cells that are not cytotoxic/suppressor T cells $\left(\mathrm{CD} 8 \beta^{+}\right)$or double-positive T cells $\left(\mathrm{CD} 4{ }^{+} \mathrm{CD} 8 \alpha^{+}\right)$. In a previous study we found that experimentally inoculated pigs with low levels of $\mathrm{CD} 8 \alpha^{+}$cells were more susceptible to swine dysentery than pigs with high levels of $\mathrm{CD} 8 \alpha^{+}$cells (Jonasson et al., 2004). It was not possible to verify this in the present study, since only two animals remained healthy after inoculation. B. hyodysenteriae whole-cell sonicate has been shown to induce an in vitro proliferation response of porcine $\mathrm{CD} 8^{+}$ $\mathrm{T}$ cells, $\mathrm{CD} 4^{+} \mathrm{CD}^{+} \mathrm{T}$ cells and $\gamma \delta \mathrm{T}$ cells (Waters et al., 1999a). Thus, it appears that $\mathrm{CD} 8^{+}$cell populations are an 


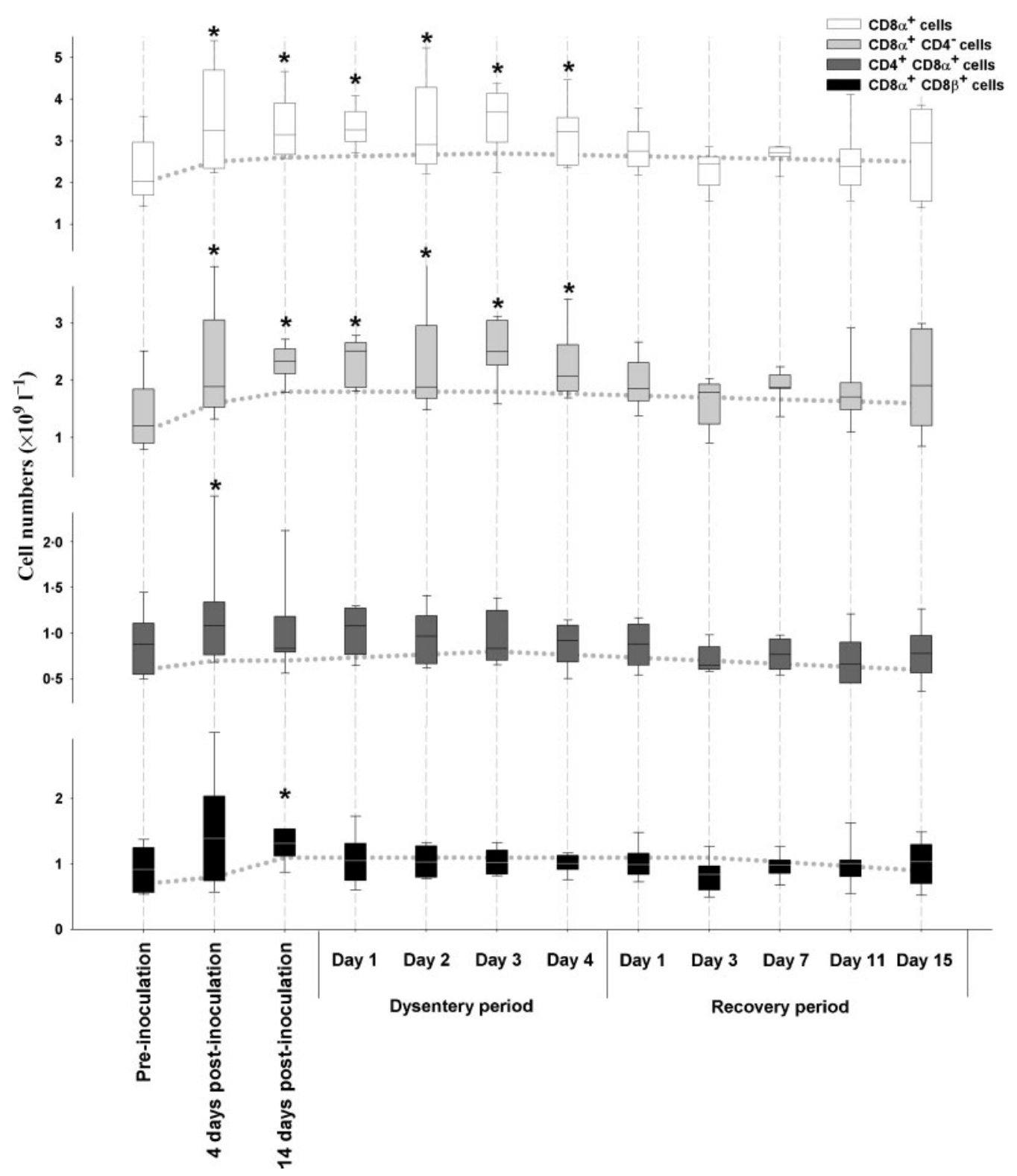

Fig. 2. $\mathrm{CD}^{+}$lymphocyte subpopulations obtained by flow cytometry: before inoculation, 4 and 14 days after inoculation, and during the swine dysentery and recovery periods. The mean incubation period was 17 days and the mean disease period was 7 days. The boundary of the box indicates the 25th percentile, the median and the 75 th percentile. Whiskers indicate the 95th and 5th percentiles. The dotted line behind each box plot shows the average for the two animals that remained healthy. Pre-, 4 days post- and 14 days post-inoculation were the same in all animals, but the remaining sampling points for the healthy animals were from 21, 28 and 35 days post-inoculation. *Significant change from pre-inoculation.

important subset in swine dysentery. In order to understand their role it may be necessary to study their cytokine production. It has been shown that $\mathrm{CD} 8{ }^{+}$cells are major producers of the cytokine IFN- $\gamma$ (Steele et al., 2002), which is important for macrophage activation (Murray, 1990). The intraepithelial region of the intestine contains large numbers of CD8 ${ }^{+}$cells (Fujihashi et al., 1990; Guy-Grand \& Vassalli, 1993). These have been shown to secrete IFN- $\gamma$ locally (Taguchi et al., 1990), and there is in vitro production of IFN- $\gamma$ by peripheral blood mononuclear cells in response to
B. hyodysenteriae bacterin (Waters et al., 1999a). Therefore, the increase of $\mathrm{CD}^{+}$cells in swine dysentery could influence the pathology and should be further investigated.

No increase in $\mathrm{CD} 4{ }^{+} \mathrm{CD} 8 \alpha^{+} \mathrm{T}$ cells or $\mathrm{CD} 8 \alpha^{+} \mathrm{CD} 8 \beta^{+}$ $\mathrm{T}$ cells was seen during dysentery or recovery. The numbers of $\gamma \delta \mathrm{T}$ cells increased throughout the recovery period (Fig. 3). These cells showed a similar pattern of increase in the animals that remained healthy (Fig. 3). This increase of $\gamma \delta \mathrm{T}$ cells has also been seen in immunization studies with 


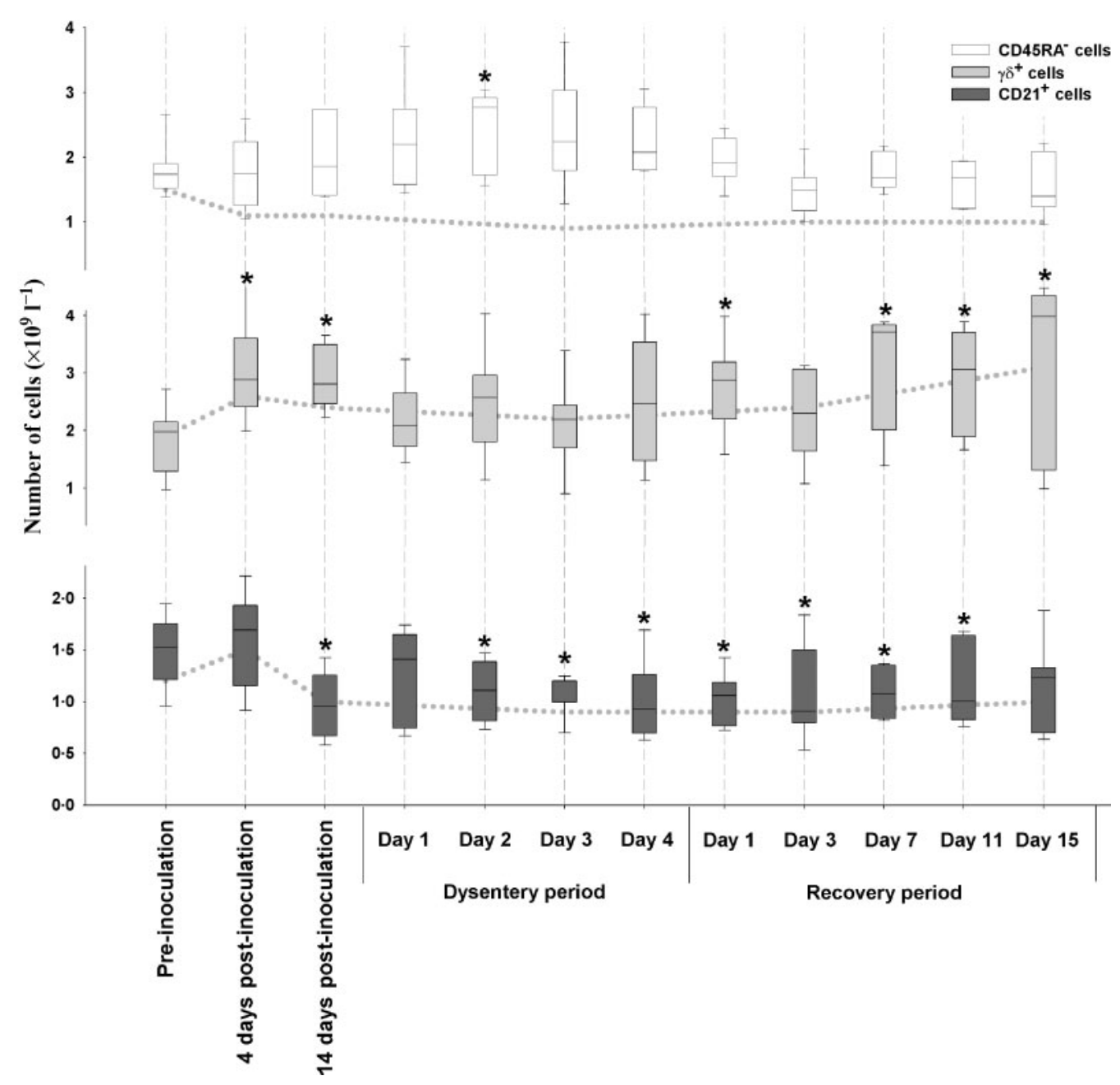

Fig. 3. Lymphocyte subpopulations obtained by flow cytometry (mean $\pm S E M$ ): before inoculation, 4 and 14 days after inoculation, and during the swine dysentery and recovery periods. The mean incubation period was 17 days and the mean disease period was 7 days. The boundary of the box indicates the 25th percentile, the median and the 75th percentile. Whiskers indicate the 95th and 5th percentiles. The dotted line behind each box plot shows the average for the two animals that remained healthy. Pre-, 4 days post- and 14 days post-inoculation were the same in all animals, but the remaining sampling points for the healthy animals were from 21, 28 and 35 days post-inoculation. *Significant change from pre-inoculation.

B. hyodysenteriae in pigs (Waters et al., 1999a, 2000; Bassaganya-Riera et al., 2001). Since the percentage of $\gamma \delta$ $\mathrm{T}$ cells in pigs generally decreases with age, the observed change in the present study is unlikely to be age related (Yang \& Parkhouse, 1996). The $\gamma \delta$ T-cell receptor has a broader specificity than the $\alpha \beta$ T-cell receptor (Constant et al., 1994; Schoel et al., 1994; Tanaka et al., 1995), and the $\gamma \delta$ T-cell-antigen recognition and subsequent activation is not dependent upon class I or class II antigen processing followed by major histocompatibility complex (MHC) presentation (Schild et al., 1994) or recirculatory migration through colonic lymph nodes (Hayday, 2000). Porcine $\gamma \delta$ $\mathrm{T}$ cells have also been shown to exhibit non-specific in vitro cytotoxicity (de Bruin et al., 1997, 2000). Thus, $\gamma \delta$ T cells could be an important part of the early defence against $B$. hyodysenteriae. Interestingly, in a previous study, pigs with high circulating levels of $\gamma \delta$ T cells before inoculation were more susceptible to the development of swine dysentery (Jonasson et al., 2004). The absence of $\gamma \delta$ T cells in $\gamma \delta$ T-cellreceptor deficient mice is associated with exaggerated intestinal damage and decreased epithelial proliferation (Komano et al., 1995). In another study, Hontecillas et al. (2005) have reported that swine dysentery induces a loss of intraepithelial colonic $\gamma \delta$ T cells, and that this is probably caused by the epithelial erosions that occur during the disease (Hutto \& Wannemuehler, 1999; Hontecillas et al., 2005). It is possible that this epithelial erosion and the subsequent loss of $\gamma \delta$ T cells may cause some of the immune responses observed during swine dysentery, through exposure to luminal antigens and bacteria other than $B$. 
hyodysenteriae. Whether this loss of local $\gamma \delta \mathrm{T}$ cells influences the levels of peripheral $\gamma \delta$ T cells is unknown. In the present study, there was no general decrease of peripheral $\gamma \delta$ T cells during clinical signs, but the two pigs with the longest episode of clinical signs (17 and 12 days versus the mean of $5 \pm 1$ days for the other animals) had the lowest levels of $\gamma \delta \mathrm{T}$ cells during disease and the recovery period.

The CD45RA ${ }^{+}$cells decreased during dysentery (data not shown) and correspondingly CD45RA ${ }^{-}$cells increased during clinical signs of swine dysentery and then returned to pre-inoculation levels during recovery (Fig. 3). These alterations were not seen in the two animals that remained healthy. CD45 gene expression is regulated so that naïve $\mathrm{T}$ cells are predominantly CD45RA ${ }^{+}$, and then their expression switches to $\mathrm{CD} 45 \mathrm{RO}^{+}$through alternative splicing when activated (Janeway, 1992). The increase of CD45RA ${ }^{-}$ cells, i.e. decrease of CD45RA ${ }^{+}$cells, could be interpreted as a decrease in naïve lymphocytes and thereby an increase in the levels of activated cells during clinical signs of dysentery.

The $\mathrm{CD} 21^{+}$cells decreased 14 days after inoculation and then remained at a lower level during the dysentery and recovery periods. There was no evidence of a B cell proliferation/increase in the peripheral blood. This does not necessarily mean that there was no activation of B cells, since local proliferation could occur that was not evident in the circulation. However, in the present study there was no decrease in CD45RA ${ }^{+}$B cells (data not shown), and in a study performed with biopsy specimens from the colon of swine-dysentery-affected pigs, the numbers of colonic B cells showed no tendency to increase during the disease (M. Jacobson, personal communication). Pigs vaccinated with B. hyodysenteriae antigens show proliferation of $\mathrm{T}$ cells, but not $\mathrm{B}$ cells, in response to in vitro stimulation with $B$. hyodysenteriae whole-cell sonicate antigens (Waters et al., 1999a). The decrease seen in the present study could be related to the decrease of $\mathrm{CD} 21^{+}$cells that has been found to occur in pigs post-weaning (Solano-Aguilar et al., 2001).

Other subpopulations that were stained for, such as $\mathrm{CD} 4^{+}$ $\mathrm{CD} 8 \alpha^{-} \mathrm{T}$ cells (data not shown), did not change during the experimental period.

\section{Antibody response}

As shown in Fig. 4, antibodies to B. hyodysenteriae were only present in sera collected during the recovery period. As is shown with the absorbed sera in Fig. 4(b), some antibodies were specific for B. hyodysenteriae antigens. The bands at $\sim 16 \mathrm{kDa}$ are in agreement with the membrane-associated lipoprotein SmpA of B. hyodysenteriae (Thomas et al., 1992; Thomas \& Sellwood, 1993), and the weaker bands at $\sim 30 \mathrm{kDa}$ are in agreement with the membrane lipoprotein BmpB (Lee et al., 2000). All except one of the swinedysentery-affected pigs developed these specific serum antibodies (data not shown). The animal without $B$. hyodysenteriae-specific antibody production did not show any differences in pathology or recovery that could be correlated with the lack of specific antibodies, but this animal showed the highest levels of cytotoxic $\left(\mathrm{CD} 8 \beta^{+}\right)$ $\mathrm{T}$ cells and double-positive (CD4 $\left.{ }^{+} \mathrm{CD} 8 \alpha^{+}\right) \mathrm{T}$ cells during incubation, and the highest level of $\mathrm{CD} 8 \alpha^{+} \mathrm{CD} 4^{-}$cells during clinical signs of dysentery. The production of $B$. hyodysenteriae-specific antibodies has been detected in sera during the acute phase of swine dysentery (Joens et al., 1985), and in colonic washings and sera 4-7 days after onset of clinical signs (Joens et al., 1984). However, their presence has not been related to recovery, but rather these antibodies (a)
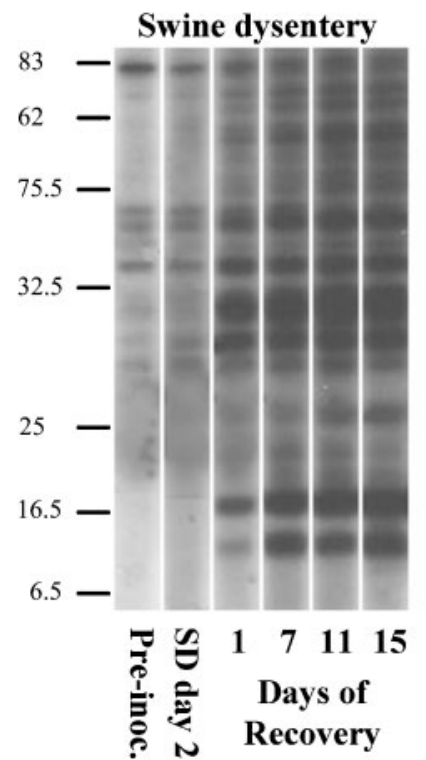

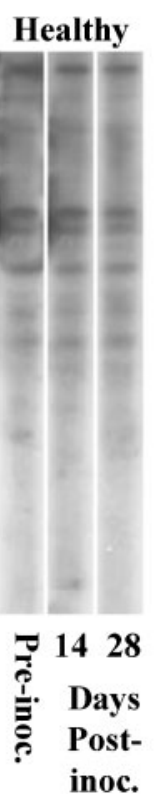

(b)

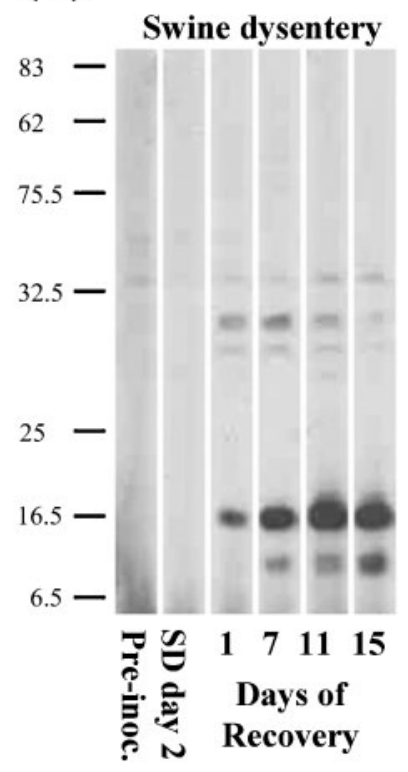

Fig. 4. Immunoblot analysis of whole-cell proteins separated by SDS-PAGE and incubated with serum from pigs before and after inoculation with $B$. hyodysenteriae. (a) Serum antibodies bound to whole-cell proteins from $B$. hyodysenteriae $\left(\mathrm{B}^{\mathrm{T}} \mathrm{C}^{\mathrm{T}}\right.$. (b) $B$. hyodysenteriae specific antigens in sera after absorption with $B$. intermedia, $B$. innocens, B. murdochii, B. pilosicoli and B. aalborgi. Molecular size $(\mathrm{kDa})$ markers are shown to the left of each panel. SD, swine dysentery; inoc., inoculation. 
have mainly been regarded as an indication of a prolonged or recent exposure to B. hyodysenteriae (Rees et al., 1989). In the present study, the recovery period coincided with the appearance of $B$. hyodysenteriae-specific serum antibodies. The presence of $B$. hyodysenteriae-specific serum antibodies in the swine-dysentery-affected pigs indicated some activation of B cells during recovery. Sera collected from the two inoculated but clinically healthy animals remained negative for antibodies to B. hyodysenteriae throughout the experimental period.

In conclusion, increased levels of circulating monocytes, neutrophils and $\mathrm{CD} 8 \alpha^{+}$cells correlate with the clinical signs of swine dysentery. These CD $8 \alpha^{+}$cells were not $\gamma \delta$ T cells, $\mathrm{CD} 8 \alpha^{+} \mathrm{CD} 8 \beta^{+} \mathrm{T}$ cells or $\mathrm{CD} 4{ }^{+} \mathrm{CD} 8 \alpha^{+} \mathrm{T}$ cells. During the recovery period, there were high levels of circulating neutrophils. Additionally, $\gamma \delta$ T cells were noted to increase during the recovery period. The dysentery-affected pigs showed decreased levels of $\mathrm{CD} 21^{+}$cells in blood during disease and recovery, but developed B. hyodysenteriaespecific antibodies from the first day of recovery. In order to understand this disease it is of importance to clarify the roles that cells play during clinical signs of swine dysentery, and the roles of cells and specific antibodies during recovery.

\section{ACKNOWLEDGEMENTS}

This study was financially supported by The Swedish Research Council for Environment, Agricultural Sciences and Spatial Planning, and the Swedish Farmers Foundation for Agricultural Research (SLF). The Swedish Research Council financed the BDLSR flow cytometer. Thanks are due to Professor Caroline Fossum, Associate Professor Birgitta Essén-Gustavsson and Dr Magdalena Jacobson for critical reading of the manuscript.

\section{REFERENCES}

Albassam, M. A., Olander, H. J., Thacker, H. L. \& Turek, J. J. (1985). Ultrastructural characterization of colonic lesions in pigs inoculated with Treponema hyodysenteriae. Can J Comp Med 49, 384-390.

Badolato, R., Wang, J. M., Murphy, W. J., Lloyd, A. R., Michiel, D. F., Bausserman, L. L., Kelvin, D. J. \& Oppenheim, J. J. (1994). Serum amyloid A is a chemoattractant: induction of migration, adhesion, and tissue infiltration of monocytes and polymorphonuclear leukocytes. J Exp Med 180, 203-209.

Bassaganya-Riera, J., Hontecillas, R., Zimmerman, D. R. \& Wannemuehler, M. J. (2001). Dietary conjugated linoleic acid modulates phenotype and effector functions of porcine CD8 $(+)$ lymphocytes. J Nutr 131, 2370-2377.

Beutler, B., Milsark, I. W. \& Cerami, A. C. (1985). Passive immunization against cachectin/tumor necrosis factor protects mice from lethal effect of endotoxin. Science 229, 869-871.

Constant, P., Davodeau, F., Peyrat, M. A., Poquet, Y., Puzo, G., Bonneville, M. \& Fournie, J. J. (1994). Stimulation of human gamma delta $\mathrm{T}$ cells by nonpeptidic mycobacterial ligands. Science 264, 267-270.

de Bruin, M. G., van Rooij, E. M., Voermans, J. J., de Visser, Y. E., Bianchi, A. T. \& Kimman, T. G. (1997). Establishment and characterization of porcine cytolytic cell lines and clones. Vet Immunol Immunopathol 59, 337-347. de Bruin, T. G., van Rooij, E. M., de Visser, Y. E., Voermans, J. J., Samsom, J. N., Kimman, T. G. \& Bianchi, A. T. (2000). Discrimination of different subsets of cytolytic cells in pseudorabies virus immune and naive pigs. J Gen Virol 81, 1529-1537.

Dhiman, T. R., Satter, L. D., Pariza, M. W., Galli, M. P., Albright, K. \& Tolosa, M. X. (2000). Conjugated linoleic acid (CLA) content of milk from cows offered diets rich in linoleic and linolenic acid. J Dairy Sci 83, 1016-1027.

Fellström, C. \& Gunnarsson, A. (1995). Phenotypical characterisation of intestinal spirochaetes isolated from pigs. Res Vet Sci 59, $1-4$.

Fujihashi, K., Taguchi, T., McGhee, J. R., Eldridge, J. H., Bruce, M. G., Green, D. R., Singh, B. \& Kiyono, H. (1990). Regulatory function for murine intraepithelial lymphocytes. Two subsets of $\mathrm{CD}^{+}, \mathrm{T}$ cell receptor- $1^{+}$intraepithelial lymphocyte $\mathrm{T}$ cells abrogate oral tolerance. J Immunol 145, 2010-2019.

Greer, J. M. \& Wannemuehler, M. J. (1989). Pathogenesis of Treponema hyodysenteriae: induction of interleukin-1 and tumor necrosis factor by a treponemal butanol/water extract (endotoxin). Microb Pathog 7, 279-288.

Guy-Grand, D. \& Vassalli, P. (1993). Gut intraepithelial T lymphocytes. Curr Opin Immunol 5, 247-252.

Harris, D. L. \& Glock, R. D. (1981). Swine dysentery. In Diseases of Swine, pp. 432-444. Edited by A. D. Leman, R. D. Glock, W. L. Mengeling, R. H. C. Penny, E. Scholl \& B. Straw. Ames, IA: Iowa State University Press.

Hayday, A. C. (2000). $\gamma \delta$ cells: a right time and a right place for a conserved third way of protection. Annu Rev Immunol 18, 975-1026.

Heegaard, P. M., Klausen, J., Nielsen, J. P., Gonzalez-Ramon, N., Pineiro, M., Lampreave, F. \& Alava, M. A. (1998). The porcine acute phase response to infection with Actinobacillus pleuropneumoniae. Haptoglobin, C-reactive protein, major acute phase protein and serum amyloid A protein are sensitive indicators of infection. Comp Biochem Physiol B Biochem Mol Biol 119, 365-373.

Hershkoviz, R., Preciado-Patt, L., Lider, O., Fridkin, M., Dastych, J., Metcalfe, D. D. \& Mekori, Y. A. (1997). Extracellular matrix-anchored serum amyloid A preferentially induces mast cell adhesion. Am J Physiol 273, 179-187.

Hontecillas, R., Wannemeulher, M. J., Zimmerman, D. R., Hutto, D. L., Wilson, J. H., Ahn, D. U. \& Bassaganya-Riera, J. (2002). Nutritional regulation of porcine bacterial-induced colitis by conjugated linoleic acid. J Nutr 132, 2019-2027.

Hontecillas, R., Bassaganya-Riera, J., Wilson, J., Hutto, D. L. \& Wannemuehler, M. J. (2005). CD4 ${ }^{+}$T-cell responses and distribution at the colonic mucosa during Brachyspira hyodysenteriaeinduced colitis in pigs. Immunology 115, 127-135.

Hutto, D. L. \& Wannemuehler, M. J. (1999). A comparison of the morphologic effects of Serpulina hyodysenteriae or its beta-hemolysin on the murine cecal mucosa. Vet Pathol 36, 412-422.

Jacobson, M., Fellström, C., Lindberg, R., Wallgren, P. \& JensenWaern, M. (2004). Experimental swine dysentery: comparison between infection models. J Med Microbiol 53, 273-280.

Janeway, C. A., Jr (1992). The T cell receptor as a multicomponent signalling machine: CD4/CD8 coreceptors and CD45 in $\mathrm{T}$ cell activation. Annu Rev Immunol 10, 645-674.

Jensen, L. E. \& Whitehead, A. S. (1998). Regulation of serum amyloid A protein expression during the acute-phase response. Biochem $J$ 334, 489-503.

Joens, L. A., Harris, D. L. \& Baum, D. H. (1979). Immunity to swine dysentery in recovered pigs. Am J Vet Res 40, 1352-1354.

Joens, L. A., Whipp, S. C., Glock, R. D. \& Neussen, M. E. (1983). Serotype-specific protection against Treponema hyodysenteriae 
infection in ligated colonic loops of pigs recovered from swine dysentery. Infect Immun 39, 460-462.

Joens, L. A., de Young, D. W., Cramer, J. C. \& Glock, R. D. (1984). The immune response of the porcine colon to swine dysentery. In Proceedings of the International Pig Veterinary Society, Ghent, Belgium, p. 187. Ghent, Belgium: International Pig Veterinary Society.

Joens, L. A., de Young, D. W., Glock, R. D., Mapother, M. E., Cramer, J. D. \& Wilcox, H. E., III (1985). Passive protection of segmented swine colonic loops against swine dysentery. Am J Vet Res 46, 2369-2371.

Jonasson, R., Johannisson, A., Jacobson, M., Fellström, C. \& Jensen-Waern, M. (2004). Differences in lymphocyte subpopulations and cell counts before and after experimentally induced swine dysentery. J Med Microbiol 53, 267-272.

Jones, H. P., Tabor, L., Sun, X., Woolard, M. D. \& Simecka, J. W. (2002). Depletion of $\mathrm{CD}^{+} \mathrm{T}$ cells exacerbates $\mathrm{CD}^{+} \mathrm{Th}$ cellassociated inflammatory lesions during murine mycoplasma respiratory disease. J Immunol 168, 3493-3501.

Komano, H., Fujiura, Y., Kawaguchi, M. \& 7 other authors (1995). Homeostatic regulation of intestinal epithelia by intraepithelial gamma delta T cells. Proc Natl Acad Sci U S A 92, 6147-6151.

La, T., Phillips, N. D., Reichel, M. P. \& Hampson, D. J. (2004). Protection of pigs from swine dysentery by vaccination with recombinant BmpB, a $29 \cdot 7 \mathrm{kDa}$ outer-membrane lipoprotein of Brachyspira hyodysenteriae. Vet Microbiol 102, 97-109.

Laemmli, U. K. (1970). Cleavage of structural proteins during the assembly of the head of bacteriophage T4. Nature 227, 680-685.

Lee, B. J., La, T., Mikosza, A. S. \& Hampson, D. J. (2000). Identification of the gene encoding $\mathrm{BmpB}$, a $30 \mathrm{kDa}$ outer envelope lipoprotein of Brachyspira (Serpulina) hyodysenteriae, and immunogenicity of recombinant $\mathrm{BmpB}$ in mice and pigs. Vet Microbiol 76, 245-257.

Lobova, D., Smola, J. \& Cizek, A. (2004). Decreased susceptibility to tiamulin and valnemulin among Czech isolates of Brachyspira hyodysenteriae. J Med Microbiol 53, 287-291.

Murray, H. W. (1990). Gamma interferon, cytokine-induced macrophage activation, and antimicrobial host defense. In vitro, in animal models, and in humans. Diagn Microbiol Infect Dis 13, 411-421.

Neef, N. A., Lysons, R. J., Trott, D. J., Hampson, D. J., Jones, P. W. \& Morgan, J. H. (1994). Pathogenicity of porcine intestinal spirochetes in gnotobiotic pigs. Infect Immun 62, 2395-2403.

Nibbelink, S. K., Sacco, R. E. \& Wannemuehler, M. J. (1997). Pathogenicity of Serpulina hyodysenteriae: in vivo induction of tumor necrosis factor and interleukin-6 by a serpulinal butanol/water extract (endotoxin). Microb Pathog 23, 181-187.

Nuessen, M. E., Birmingham, J. R. \& Joens, L. A. (1982). Biological activity of a lipopolysaccharide extracted from Treponema hyodysenteriae. Infect Immun 37, 138-142.

Pescovitz, M. D., Sakopoulos, A. G., Gaddy, J. A., Husmann, R. J. \& Zuckermann, F. A. (1994). Porcine peripheral blood CD $4^{+} / \mathrm{CD} 8^{+}$ dual expressing T-cells. Vet Immunol Immunopathol 43, 53-62.

Rees, A. S., Lysons, R. J., Stokes, C. R. \& Bourne, F. J. (1989). Antibody production by the pig colon during infection with Treponema hyodysenteriae. Res Vet Sci 47, 263-269.

Sacco, R. E., Nibbelink, S. K., Baarsch, M. J., Murtaugh, M. P. \& Wannemuehler, M. J. (1996). Induction of interleukin (IL)-1beta and IL-8 mRNA expression in porcine macrophages by lipopolysaccharide from Serpulina hyodysenteriae. Infect Immun 64, 4369-4372.

Sacco, R. E., Hutto, D. L., Waters, W. R., Xiasong, L., Kehrli, M. E., Jr, Zuckermann, F. A. \& Wannemuehler, M. J. (2000). Reduction in inflammation following blockade of CD18 or CD29 adhesive pathways during the acute phase of a spirochetal-induced colitis in mice. Microb Pathog 29, 289-299.

Schild, H., Mavaddat, N., Litzenberger, C., Ehrich, E. W., Davis, M. M., Bluestone, J. A., Matis, L., Draper, R. K. \& Chien, Y. H. (1994). The nature of major histocompatibility complex recognition by gamma delta T cells. Cell 76, 29-37.

Schoel, B., Sprenger, S. \& Kaufmann, S. H. (1994). Phosphate is essential for stimulation of $\mathrm{V} \gamma 9 \mathrm{~V} \delta 2 \mathrm{~T}$ lymphocytes by mycobacterial low molecular weight ligand. Eur J Immunol 24, 1886-1892.

Solano-Aguilar, G. I., Vengroski, K. G., Beshah, E., Douglass, L. W. \& Lunney, J. K. (2001). Characterization of lymphocyte subsets from mucosal tissues in neonatal swine. Dev Comp Immunol 25, 245-263.

Steele, C., Zheng, M., Young, E., Marrero, L., Shellito, J. E. \& Kolls, J. K. (2002). Increased host resistance against Pneumocystis carinii pneumonia in $\gamma \delta$ T-cell-deficient mice: protective role of gamma interferon and $\mathrm{CD}^{+}{ }^{+} \mathrm{T}$ cells. Infect Immun 70, 5208-5215.

Taguchi, T., McGhee, J. R., Coffman, R. L., Beagley, K. W. Eldridge, J. H., Takatsu, K. \& Kiyono, H. (1990). Analysis of Th1 and Th2 cells in murine gut-associated tissues. Frequencies of $\mathrm{CD}^{+}{ }^{+}$and $\mathrm{CD}^{+} \mathrm{T}$ cells that secrete IFN-gamma and IL-5. J Immunol 145, 68-77.

Tanaka, Y., Morita, C. T., Nieves, E., Brenner, M. B. \& Bloom, B. R. (1995). Natural and synthetic non-peptide antigens recognized by human gamma delta T cells. Nature 375, 151-158.

Taylor, D. J. \& Alexander, T. J. (1971). The production of dysentery in swine by feeding cultures containing a spirochaete. Br Vet J 127, $58-61$.

Thomas, W. \& Sellwood, R. (1993). Molecular cloning, expression, and DNA sequence analysis of the gene that encodes the 16kilodalton outer membrane lipoprotein of Serpulina hyodysenteriae. Infect Immun 61, 1136-1140.

Thomas, W., Sellwood, R. \& Lysons, R. J. (1992). A 16-kilodalton lipoprotein of the outer membrane of Serpulina (Treponema) hyodysenteriae. Infect Immun 60, 3111-3116.

Towbin, H., Staehelin, T. \& Gordon, J. (1979). Electrophoretic transfer of proteins from polyacrylamide gels to nitrocellulose sheets: procedure and some applications. Proc Natl Acad Sci U S A 76, $4350-4354$

Van Snick, J. (1990). Interleukin-6: an overview. Annu Rev Immunol 8, 253-278.

Waters, W. R., Pesch, B. A., Hontecillas, R., Sacco, R. E., Zuckermann, F. A. \& Wannemuehler, M. J. (1999a). Cellular immune responses of pigs induced by vaccination with either a whole cell sonicate or pepsin-digested Brachyspira (Serpulina) hyodysenteriae bacterin. Vaccine 18, 711-719.

Waters, W. R., Sacco, R. E., Dorn, A. D., Hontecillas, R., Zuckermann, F. A. \& Wannemuehler, M. J. (1999b). Systemic and mucosal immune responses of pigs to parenteral immunization with a pepsin-digested Serpulina hyodysenteriae bacterin. Vet Immunol Immunopathol 69, 75-87.

Waters, W. R., Hontecillas, R., Sacco, R. E., Zuckermann, F. A., Harkins, K. R., Bassaganya-Riera, J. \& Wannemuehler, M. J. (2000). Antigen-specific proliferation of porcine CD $8 \alpha \alpha$ cells to an extracellular bacterial pathogen. Immunology 101, 333-341.

Whipp, S. C., Robinson, I. M., Harris, D. L., Glock, R. D., Matthews, P. J. \& Alexander, T. J. (1979). Pathogenic synergism between Treponema hyodysenteriae and other selected anaerobes in gnotobiotic pigs. Infect Immun 26, 1042-1047.

Wilcock, B. P. \& Olander, H. J. (1979). Studies on the pathogenesis of swine dysentery. I. Characterization of the lesions in colons and 
colonic segments inoculated with pure cultures or colonic content containing Treponema hyodysenteriae. Vet Pathol 16, 450-465.

Wright, J. C., Wilt, G. R., Reed, R. B. \& Powe, T. A. (1989). Use of an enzyme-linked immunosorbent assay for detection of Treponema hyodysenteriae infection in swine. J Clin Microbiol 27, 411-416.

Xu, L., Badolato, R., Murphy, W. J., Longo, D. L., Anver, M., Hale, S., Oppenheim, J. J. \& Wang, J. M. (1995). A novel biologic function of serum amyloid A. Induction of $\mathrm{T}$ lymphocyte migration and adhesion. J Immunol 155, 1184-1190.

Yang, H. \& Parkhouse, R. M. (1996). Phenotypic classification of porcine lymphocyte sub-populations in blood and lymphoid tissues. Immunology 98, 76-83.

Zuckermann, F. A. \& Husmann, R. J. (1996). Functional and phenotypic analysis of porcine peripheral blood CD4/CD8 double-positive $\mathrm{T}$ cells. Immunology 87, 500-512. 